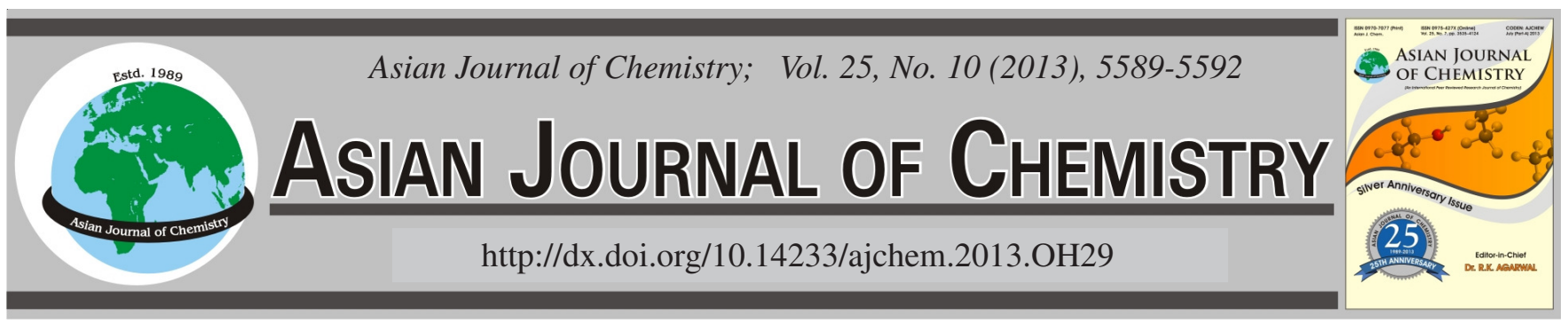

\title{
Surface Modification of Nano-Silicon Nitride with Silane Coupling Agent $\dagger$
}

\author{
XIAODONG W $\mathrm{ANG}^{1,2, *}$ and XINJUN WAN ${ }^{1}$
}

${ }^{1}$ Department of Chemistry and Material Science, Chaohu University, Chaohu 238000, P.R. China

${ }^{2}$ AnHui Province Key Laboratory of Environment-friendly Polymer Materials, Anhui University, Hefei 230039, P.R. China

*Corresponding author: E-mail: sdjc2000@yahoo.com.cn

\begin{abstract}
In this work, a silane coupling agent was used for surface modification of native nano-sized silicon nitride $\left(\mathrm{Si}_{3} \mathrm{~N}_{4}\right)$ powder. According to the spectra of FT-IR and TGA, it can be inferred that this coupling agent covalently bonds on the surface of nano-Si $\mathrm{N}_{3} \mathrm{~N}_{4}$ particles and an organic coating layer was formed. The surface free energy experiments showed that the hydrophobic property of nano-Si $\mathrm{N}_{4}$ modified with coupling agent was improved obviously. Analysis of nanoparticle size and TEM revealed that the modified nano-Si $\mathrm{N}_{4}$ possessed good dispersibility and the average diameter was less than $100 \mathrm{~nm}$.
\end{abstract}

Key Words: Silicon nitride, Surface modification, Nanocomposite, Dispersibility.

\section{INTRODUCTION}

Composite materials are composed of metallic, inorganic non-metallic or polymer material and they are a kind of multiphase materials, which possess a superior cooperative performance. Composite materials based on polymer with nano-size is a kind of inorganic-organic composite materials and the inorganic fillers are dispersed in the polymer with nano-size.

Silicon nitride $\left(\mathrm{Si}_{3} \mathrm{~N}_{4}\right)$ is an important inorganic ceramic material used various applications due to its high strength, high fracture toughness, high thermal-shock resistance, low coefficient of thermal expantion and good wear resistance ${ }^{1-5}$. It may be an effective filler of polymeric aterials for the properties improvement. Our research group is preparing nano- $\mathrm{Si}_{3} \mathrm{~N}_{4} / \mathrm{PPS}$ composites that may be exhibit unique hybrid properties including good heat-resistance and good dynamic mechanical properties. However, it is difficult to prepare polymer-based nanocomposites from a conventional polymer because of the strong tendency of nanoparticles to agglomerate. To break down the nanoparticle agglomerates and for improving the dispersivity of nanosized particles in polymer matrix, the technology of surface-modification is used for producing nanostructural composites.

In this study, a surface modification strategy with a silane coupling agent for $\mathrm{Si}_{3} \mathrm{~N}_{4}$ was developed so that the the modified nano- $\mathrm{Si}_{3} \mathrm{~N}_{4}$ can be added to the PPS matrix for improving their compatibility and nanoparticles'dispersibility.

\section{EXPERIMENTAL}

The silicon nitride powder used in this study was a commercial product from Kaier Nano-materials Co. Ltd., Hefei, P.R. China with following characteristics: average particle size $20-40 \mathrm{~nm}$, specific surface area $>115 \mathrm{~m}^{2} \cdot \mathrm{g}^{-1}$, total oxygen $<0.62 \%$ (wt).

Modification agent was purchased from Nanjing Shuguang Chemicals Co., Nanjing, P.R. China. Commercial name: KH845-4; chemical name: bis-( $\gamma$-triethoxysilylpropyl)-tetrasulfide. Acetone (A.R) and ethanol (A.R) was purchased from Shanghai reagent company of China national pharmaceutical group Co., Shanghai, P.R. China and petroleum ether (A.R) was purchased from Hangzhou refinery of China petrochemical Co., Hangzhou, P.R. China.

Surface modification: Nano- $\mathrm{Si}_{3} \mathrm{~N}_{4}$ powders were dispersed in petroleum ether and a certain amount (8-18\% of total mass) of coupling agent was added into the flask, mixing round with high speed at $40{ }^{\circ} \mathrm{C}$ for $4 \mathrm{~h}$, then vacuum drying for $24 \mathrm{~h}$.

Characterization and measurement: Native nano- $\mathrm{Si}_{3} \mathrm{~N}_{4}$ powders and modified nano- $\mathrm{Si}_{3} \mathrm{~N}_{4}$ powders were investigated by FT-IR (Neuxs-870, Nicole-t); TGA(Pyris-I, Perkin Elmer); Size distuibutions analyzer (Zetasizer 3000 HS, Malvern), TEM (JEM-100SX, JE-OL). Contact angle and surface free energy were investigated by contact angle measuring instrument (DSA 10-MK2,KRüss Gmb H). 


\section{RESULTS AND DISCUSSION}

FT-IR analysis of powder: The surface region of nano$\mathrm{Si}_{3} \mathrm{~N}_{4}$ powder has a significant amount of of $\mathrm{Si}_{2}-\mathrm{NH}, \mathrm{Si}-\mathrm{NH}_{2}$ and $\mathrm{Si}-\mathrm{OH}$ groups ${ }^{3}$. In Fig. 1, v(OH) (hydrogen bonded) + $v(\mathrm{NH})$ combination band observed at $3422 \mathrm{~cm}^{-16}$. The detection of absorption at $1064 \mathrm{~cm}^{-1}$ as well as of a broad and band at $487 \mathrm{~cm}^{-1}$ in our sample, is probably indicative of the presence of $\mathrm{SiO}_{2}{ }^{7}$ The band at $1633 \mathrm{~cm}^{-1}$ is assigned to the $\mathrm{N}-\mathrm{H}$ shear vibration, $974 \mathrm{~cm}^{-1}$ is assigned to the back bone vibrations of $\mathrm{Si}-\mathrm{N}-\mathrm{Si}$ and $1385 \mathrm{~cm}^{-1}$ is attributed to the bending mode of hydroxyl groups.

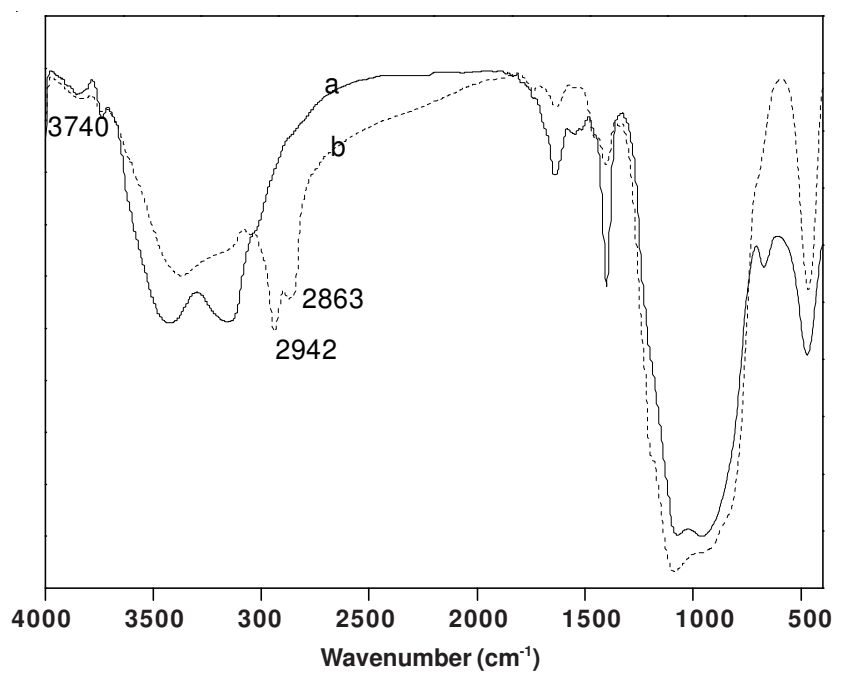

Fig. 1. FT-IR spectra of nano- $\mathrm{Si}_{3} \mathrm{~N}_{4}$ (a) and modified nano- $\mathrm{Si}_{3} \mathrm{~N}_{4}$ (b)

For the modified nano- $\mathrm{Si}_{3} \mathrm{~N}_{4}$ (Fig. 1), the peaks at 2942 and $2863 \mathrm{~cm}^{-1}$ are related to $-\mathrm{CH}_{2},-\mathrm{CH}_{3}$ asymmetric stretching mode. This proved that the coupling agent had been tightly absorbed at the surface of nano $-\mathrm{Si}_{3} \mathrm{~N}_{4}$ by chemisorption and it is still exist in the modified powders even after being extracted by Soxhlets extractor in acetone.

TGA of nano- $\mathrm{Si}_{3} \mathrm{~N}_{4}$ : Thermal stability of nano- $\mathrm{Si}_{3} \mathrm{~N}_{4}$, modified nano- $\mathrm{Si}_{3} \mathrm{~N}_{4}$ were measured by dynamic thermogravimetric analysis. The surface modified nano- $\mathrm{Si}_{3} \mathrm{~N}_{4}$ sample was analyzed after being washed with acetone in Soxhlet extractor for $72 \mathrm{~h}$.

Fig. 2 is TG curve of nano- $\mathrm{Si}_{3} \mathrm{~N}_{4}$ and modified nano- $\mathrm{Si}_{3} \mathrm{~N}_{4}$ (the heating rate was monitored at $20^{\circ} \mathrm{C} / \mathrm{min}$ ). As shown in the TG curve, the thermal decomposition of native nano- $\mathrm{Si}_{3} \mathrm{~N}_{4}$ begins at about $40{ }^{\circ} \mathrm{C}$ and the continuous mass loss can be seen from 40 to $200^{\circ} \mathrm{C}$. This is likely due to a series of reactions happening on the surface of nano- $\mathrm{Si}_{3} \mathrm{~N}_{4}$ between surface groups or some physical and chemical adsorption substances, then the desorption of $\mathrm{H}_{2} \mathrm{O}, \mathrm{NH}_{3}$ and etc. from the surface of nano$\mathrm{Si}_{3} \mathrm{~N}_{4}$ with increasing temperature results in the continuous mass loss. In contrast with native nano- $\mathrm{Si}_{3} \mathrm{~N}_{4}$, the thermal decomposition process of modified nano- $\mathrm{Si}_{3} \mathrm{~N}_{4}$ can be divided into several stages. The first stage started from 40 to $160{ }^{\circ} \mathrm{C}$, the mass loss is only about $1 \%$. The second stage is in the range of $160-340{ }^{\circ} \mathrm{C}$. This stage is identical with the main thermal decomposition stage. Thus, we consider that most of the coupling agent coats on the surface of nano- $\mathrm{Si}_{3} \mathrm{~N}_{4}$ particles and strong chemical bonding establishes between the coupling agent and nano- $\mathrm{Si}_{3} \mathrm{~N}_{4}$. The third stages of decomposition is above $340{ }^{\circ} \mathrm{C}$ and powder quality changed little. Compared with native nano- $\mathrm{Si}_{3} \mathrm{~N}_{4}$ and modified nano- $\mathrm{Si}_{3} \mathrm{~N}_{4}$, the result indicates that owing to the strong chemical bonding, the decreasing number of $-\mathrm{NH}_{2}$ and -OH group on the surface of modified nano $-\mathrm{Si}_{3} \mathrm{~N}_{4}$ results in the reduction of gas desorption quantity on the surface of modified nano $-\mathrm{Si}_{3} \mathrm{~N}_{4}$ below $210^{\circ} \mathrm{C}$. The thermal stability of modified nano- $\mathrm{Si}_{3} \mathrm{~N}_{4}$ has been proved.

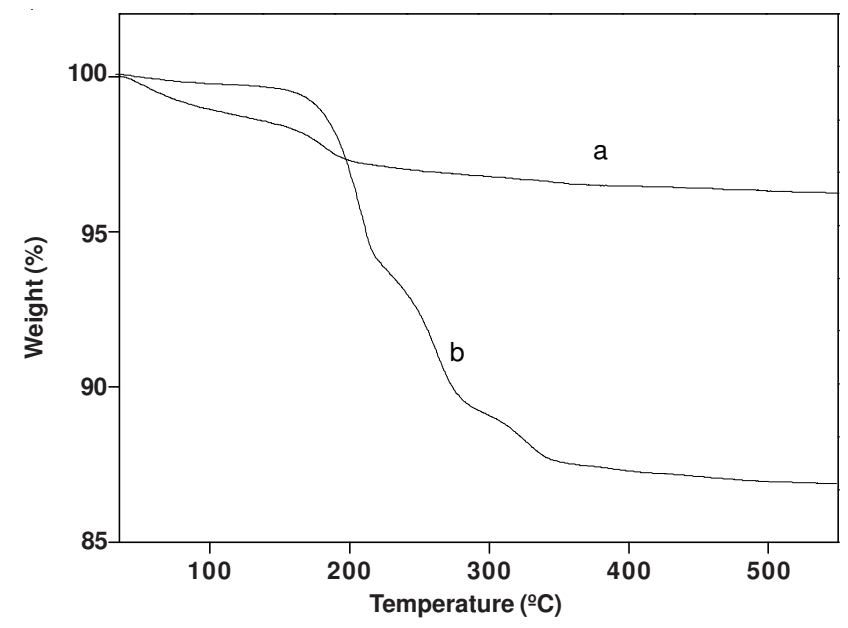

Fig. 2. TG curves of nano- $\mathrm{Si}_{3} \mathrm{~N}_{4}$ (a) and modified nano- $\mathrm{Si}_{3} \mathrm{~N}_{4}$ (b)

Analysis of nanoparticle size and distribution: The number average diameter and size distribution of nano- $\mathrm{Si}_{3} \mathrm{~N}_{4}$ suspension were analyzed using size distributions analyzer (3000 HS, Malvern) (Fig. 3). The nano- $\mathrm{Si}_{3} \mathrm{~N}_{4}$ suspension in alcohol was prepared through ultrasonic dispersion for $0.5 \mathrm{~h}$. According to the result, the average diameter of native nano$\mathrm{Si}_{3} \mathrm{~N}_{4}$ is about $110 \mathrm{~nm}$ while that of modified nano- $\mathrm{Si}_{3} \mathrm{~N}_{4}$ decreased obviously. It was suggested that the dispersing effect of nano- $\mathrm{Si}_{3} \mathrm{~N}_{4}$ in alcohol be improved obviously after modified.

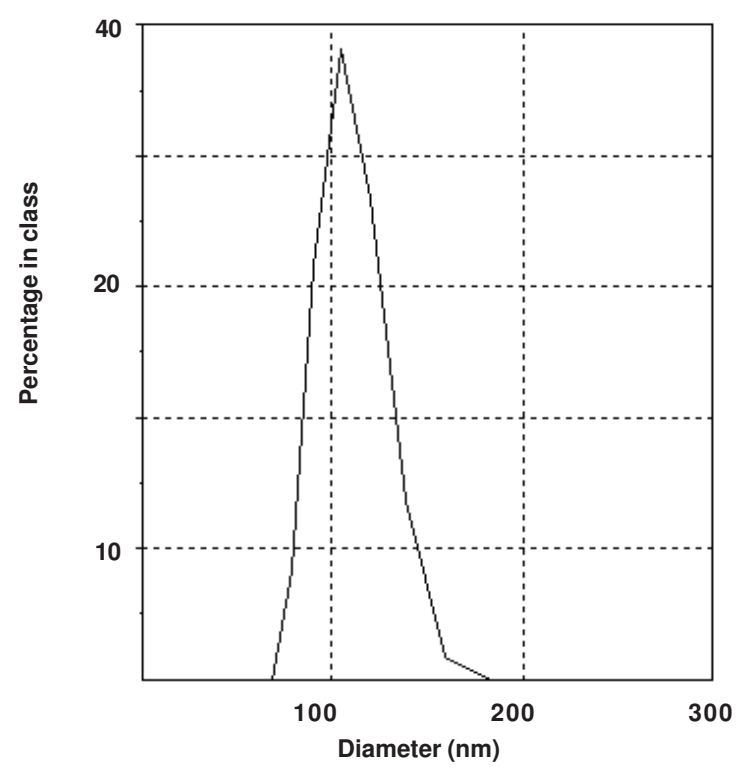

a1. Volume distribution of nano- $\mathrm{Si}_{3} \mathrm{~N}_{4}$ 


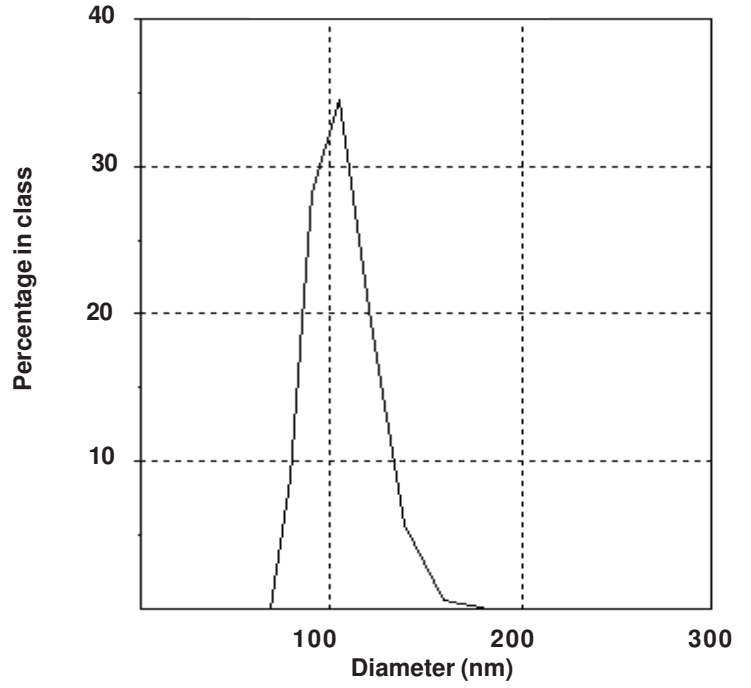

a2. Number distribution of nano- $\mathrm{Si}_{3} \mathrm{~N}_{4}$

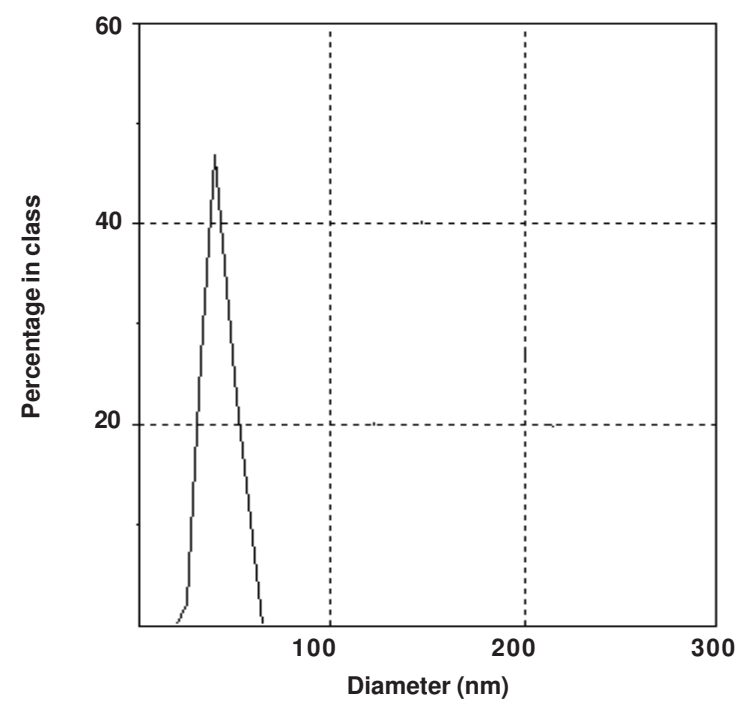

b1. Volume distribution of modified nano- $\mathrm{Si}_{3} \mathrm{~N}_{4}$

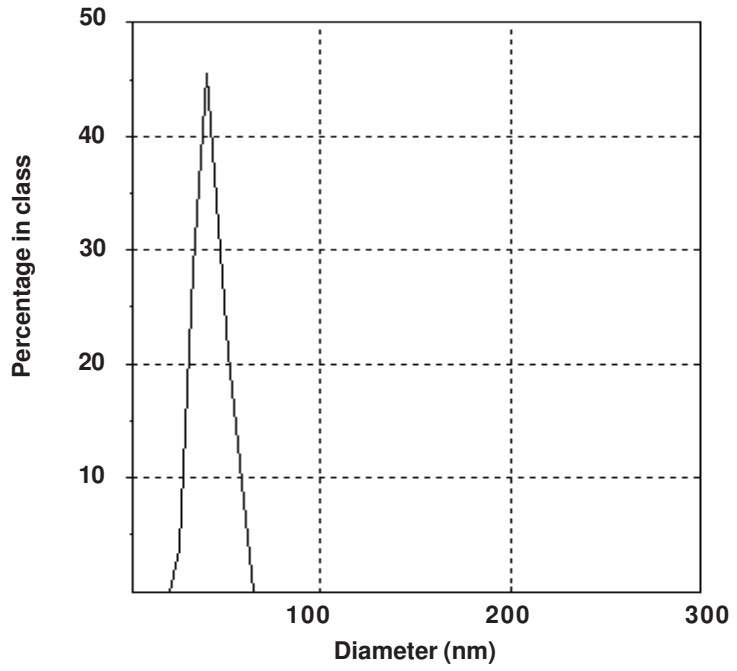

b2. Number distribution of modified nano- $\mathrm{Si}_{3} \mathrm{~N}_{4}$

Fig. 3. Size distribution of nano-Si $\mathrm{N}_{4}\left(\mathrm{a} 1\right.$, a2) and modified nano- $\mathrm{Si}_{3} \mathrm{~N}_{4}$ (b1, b2)
The native nano- $\mathrm{Si}_{3} \mathrm{~N}_{4}$ particles were dispersed poorly in alcohol and the serious agglomerations were formed due to the existence of Si-OH group on the surface of the native nano$\mathrm{Si}_{3} \mathrm{~N}_{4}$ powders. Compared with the native powders, the nano$\mathrm{Si}_{3} \mathrm{~N}_{4}$ modified with $\mathrm{KH}-845-4$ showed good dispersibility in alcohol. Because of the new chemical bond's forming between the coupling agent and nano-particles, the interaction among nano-particles was broken down and the agglomeration was controlled effectively.

Analysis of surface free energy: The change of surface hydrophilicity was investigated by contact angle measurements. Surface free energy was calculated by corresponding contact angle. Table- 1 shows an obvious change of surface free energy after modifying nano- $\mathrm{Si}_{3} \mathrm{~N}_{4}$ surfaces. After the surface modification, the surface free energy decreased from 108.12 to $25.36 \mathrm{~J} / \mathrm{m}^{2}$, suggesting increased surface hydrophobicity. These changes are likely due to the carbon backbone of the silane coupling agent, which is hydrophobic. Thus, it is concluded that the nano- $\mathrm{Si}_{3} \mathrm{~N}_{4}$ modified with coupling agent can be dispersed in polymer more easily than native nano$\mathrm{Si}_{3} \mathrm{~N}_{4}$ powder.

\begin{tabular}{lcccc}
\multicolumn{5}{c}{ TABLE-1 } \\
SURFACE FREE ENERGY OF NANO-Si ${ }_{3} \mathrm{~N}_{4}$ at $20{ }^{\circ} \mathrm{C}$ \\
\hline \multirow{2}{*}{ Sample } & Different & \\
\cline { 2 - 5 } & $0 \%$ & $9 \%$ & $10 \%$ & $12 \%$ \\
\hline Surface energy $\left({\left.\mathrm{J} . \mathrm{m}^{-2}\right)}^{-2}\right.$ & 108.12 & 77.60 & 42.30 & 25.36 \\
\hline
\end{tabular}

Comparison of nano-Si $\mathbf{i}_{3} \mathrm{~N}_{4}$ and modified nano-Si $\mathrm{S}_{3} \mathrm{~N}_{4}$ 's dispersion by TEM: TEM photographs of native nano- $\mathrm{Si}_{3} \mathrm{~N}_{4}$ and modified nano- $\mathrm{Si}_{3} \mathrm{~N}_{4}$ suspensions in alcohol, prepared with ultrasonic vibrating method, are shown in Fig. 4. The obvious agglomeration can be seen in the photograph of native nano$\mathrm{Si}_{3} \mathrm{~N}_{4}$ [Fig. 4(a)] while a better dispersion can be seen in the photograph of modified nano- $\mathrm{Si}_{3} \mathrm{~N}_{4}$ [Fig. 4(b)]. Based on Fig. 4 , the conclusion can be drawn that the surface modification effectively improved the dispersablity of nano- $\mathrm{Si}_{3} \mathrm{~N}_{4}$ in acetone, the size of particles is less than that of the unmodified nano$\mathrm{Si}_{3} \mathrm{~N}_{4}$. And, Fig. 4(b) shows that the coating layers are clearly seen as the gray area, which coated on the surface of nano$\mathrm{Si}_{3} \mathrm{~N}_{4}$ particles and reduced the agglomerations. This suggests that condensation reaction should take place on the surface of nano- $\mathrm{Si}_{3} \mathrm{~N}_{4}$ particles, then the organic chain of the agent is grafted onto the nano-particles surface, thus the surface free energy reduced and the agglomeration was controlled.

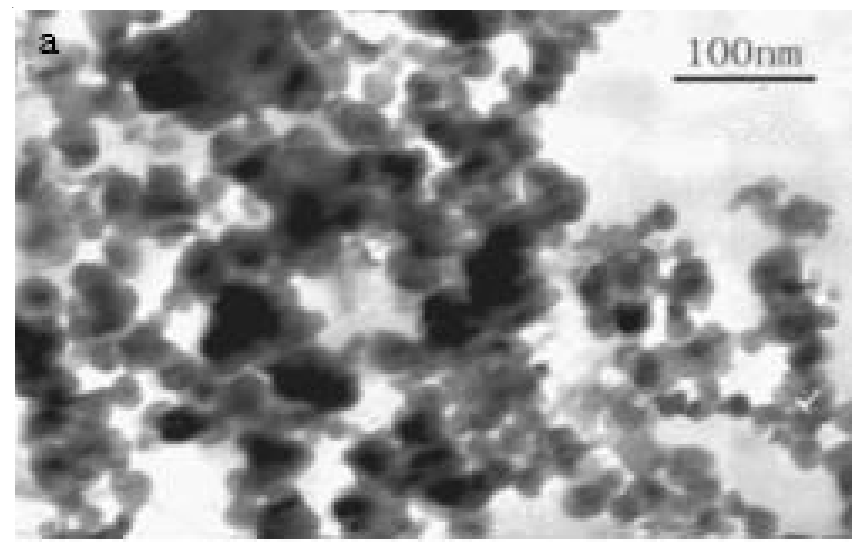




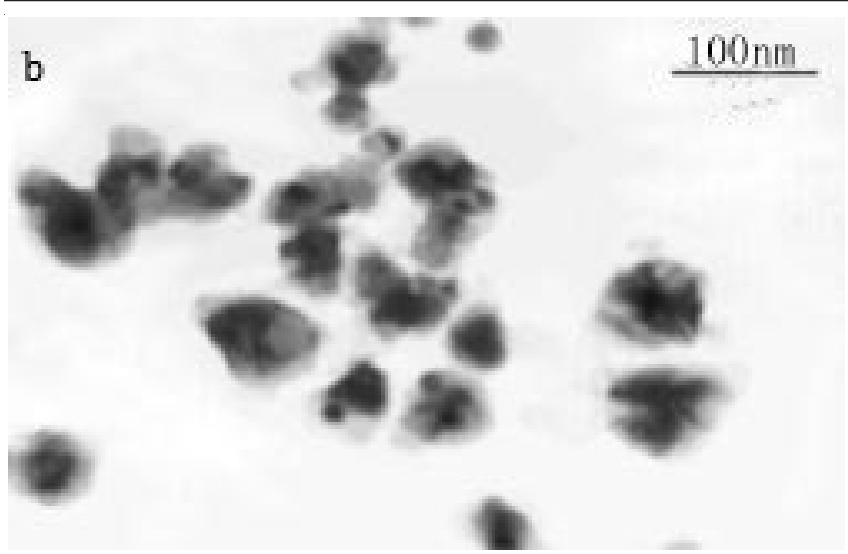

Fig. 4. TEM micrographs of nano- $\mathrm{Si}_{3} \mathrm{~N}_{4}$ (a) modified nano- $\mathrm{Si}_{3} \mathrm{~N}_{4}$ (b)

\section{Conclusion}

Nano-Si ${ }_{3} \mathrm{~N}_{4}$ powder can be modified with silane coupling agent, which may be applied to prepare polymer composites. An organic coating layer formed on the surface of nano- $\mathrm{Si}_{3} \mathrm{~N}$ powders and chemical bond combination happened between the coupling agent and nano- $\mathrm{Si}_{3} \mathrm{~N}_{4}$ powders surface. The hydrophobic property of nano- $\mathrm{Si}_{3} \mathrm{~N}_{4}$ modified with coupling agent was improved obviously. Modified nano- $\mathrm{Si}_{3} \mathrm{~N}_{4}$ possessed good dispersibility and the average diameter was less than 100 nm.

\section{ACKNOWLEDGEMENTS}

The authors are grateful for the support of Anhui Province Key Laboratory of Environment-friendly Polymer Materials (Grant KF2011003).

\section{REFERENCES}

1. J. Wippler, S. Fünfschilling, F. Fritzen, T. Böhlke and M.J. Hoffmann, Acta Mater., 59, 6029 (2011).

2. N.I. Fainer, M.L. Kosinova, Yu. M. Rumyantsev and F.A. Kuznetsov, J. Struct. Chem., 45, S65 (2004).

3. S.M. Castanho, R. Moreno and J.L.G. Fierro, J. Mater. Sci., 32, 157 (1997).

4. G. Busca, V. Lorenzelli, M.I. Baraton, P. Quintard and R. Marchand, J. Mol. Struct., 143, 525 (1986).

5. K.A. Kazakyavichyus, D.V. Narbutene, E.N. Chasovskoi, A.F. Batura and V.G. Verevka, Strength Mater, 20, 1477 (1988).

6. M.I. Baraton, W. Chang and B.H. Kear, J. Phys. Chem., 100, 16647 (1996).

7. Q.C. Zhao, W.M. Chen and Q.R. Zhu, Nanotechnology, 15, 961 (2004). 